\title{
Flow-Diversion Treatment for Unruptured Nonsaccular Intracranial Aneurysms of the Posterior and Distal Anterior Circulation: A Meta-Analysis
}

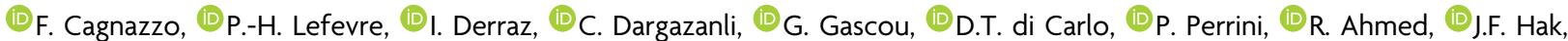

(1)C. Riquelme, 고. Bonafe, and (1) V. Costalat

\section{ABSTRACT}

BACKGROUND: Treatment management and outcomes of unruptured nonsaccular aneurysms are different compared with their saccular counterparts.

PURPOSE: Our aim was to analyze the outcomes after flow diversion among nonsaccular unruptured lesions.

DATA SOURCES: A systematic search of 3 data bases (2005-2019) was performed according to Preferred Reporting Items for Systematic Reviews and Meta-Analyses (PRISMA) guidelines.

STUDY SELECTION: We included studies reporting flow diversion for nonsaccular unruptured aneurysms of the posterior and distal anterior circulations. Anterior circulation lesions were included if located distal to the petrocavernous and supraclinoid ICA (MCA, Al, anterior communicating artery, A2). Giant dolichoectatic holobasilar lesions were excluded because of their poor treatment outcomes.

DATA ANALYSIS: Aneurysm occlusion and complication rates were calculated (random effects meta-analysis).

DATA SYNTHESIS: We included 15 studies (213 aneurysms). The long-term adequate occlusion rate was 85.3\% (137/168; 95\% Cl, 78.2\%$\left.92.4 \% ; I^{2}=42.3 \%\right)$. Treatment-related complications were $17.4 \%\left(41 / 213 ; 95 \% \mathrm{Cl}, 12.45 \%-22.4 \% ; I^{2}=0 \%\right)$. Overall, $15 \%(37 / 213 ; 95 \% \mathrm{Cl}$, $\left.10 \%-20 \% ; 1^{2}=0 \%\right)$ were ischemic events. Procedure-related morbidity was $8 \%\left(20 / 213 ; 95 \% \mathrm{Cl}, 5 \%-12 \% ; 1^{2}=0 \%\right)$. Fusiform or dissecting types had comparable adequate occlusion (116/146 =83\%; 95\% Cl, 74\%-92\%; $I^{2}=48 \%$ versus $33 / 36=89 \% ; 95 \% \mathrm{Cl}, 80 \%-98 \%$; $\left.\mathrm{I}^{2}=0 \% ; P=.31\right)$ and complication rates $\left(35 / 162=17 \% ; 95 \% \mathrm{Cl}, 10 \%-25 \% ; I^{2}=24 \%\right.$ versus $11 / 51=19 \% ; 95 \% \mathrm{Cl}, 10 \%-31 \% ; I^{2}=0 \%$; $P=.72)$. Aneurysm size $(>10$ versus $\leq 10 \mathrm{~mm})$ was independently associated with a higher rate of complications $(\mathrm{OR}=6.6 ; 95 \% \mathrm{Cl}$, $1.3-15 ; P=.02)$. The rate of ischemic events after discontinuation of the antiplatelet therapy was $5 \%\left(5 / 93 ; 95 \% \mathrm{Cl}, 2 \%-9 \% ; I^{2}=0 \%\right)$.

LIMITATIONS: Small and retrospective studies were available for this meta-analysis.

CONCLUSIONS: Unruptured nonsaccular aneurysms located in the posterior and distal anterior circulations can be effectively treated with flow diversion. Nevertheless, treatment-related complications are not negligible, with about $15 \%$ ischemic events and $8 \%$ morbidity. Larger size $(>10 \mathrm{~mm})$ significantly increases the risk of procedure-related adverse events.

ABBREVIATIONS: $\mathrm{AC}=$ anterior circulation; $\mathrm{FD}=$ flow diversion; IQR $=$ interquartile range; $\mathrm{PC}=$ posterior circulation

$F^{\prime}$ usiform and dissecting aneurysms are defined as circumferential dilation of an intracranial artery, without a neck. ${ }^{1}$ These lesions are uncommon compared with their saccular counterparts, presenting a different pathophysiology, natural history, and treatment management. ${ }^{2}$ Accordingly, procedure-related outcomes after endovascular treatment of these lesions should be explored separately. When we investigated the literature, very few series focused on the flow diversion (FD) treatment of nonsaccular lesions, and most of the available results were

Received August 28, 2019; accepted after revision October 14.

From the Neuroradiology Department (F.C., P.-H.L., I.D., C.D., G.G., R.A., J.F.H., C.R.,

A.B., V.C.), CHU Gui De Chauliac, Montpellier, France; and Department of

Neurosurgery (D.T.d.C., P.P.), University of Pisa, Pisa, Italy. derived from a combination of saccular and nonsaccular aneurysms. Thus, the evidence surrounding treatment outcomes of FD among nonsaccular aneurysms requires further evaluation. We performed a meta-analysis exploring the angiographic and clinical outcomes of the off-label use of FD for nonsaccular posterior circulation lesions and nonsaccular

Please address correspondence to Federico Cagnazzo, MD, Neuroradiology Department, CHU Gui De Chauliac, 80 Ave Augustin Fliche, 34000 Montpellier, France; e-mail: f.cagnazzo86@gmail.com

$\equiv$ Indicates article with supplemental on-line appendix and tables.

Indicates article with supplemental on-line photos.

http://dx.doi.org/10.3174/ajnr.A6352 
anterior circulation aneurysms in distal locations (MCA, A1, anterior communicating artery, pericallosal segment).

\section{MATERIALS AND METHODS}

Literature Search

A comprehensive literature search of Scopus, PubMed, and Ovid EMBASE was performed for studies published from January 2005 to July 2019. The Preferred Reporting Items for Systematic Reviews and Meta-Analyses (PRISMA; http://prisma-statement. org/) guidelines were followed. ${ }^{3}$ The search strategy is described in On-line Table 1. The included studies are reported in On-line Table 2. The main inclusion criteria were the following: studies reporting series of FD treatment of unruptured nonsaccular aneurysms located in the anterior and posterior circulations. When reported in the article, nonsaccular aneurysms were classified as dissecting and fusiform aneurysms. Dissecting aneurysms were, in general, defined as lesions resulting from an injury to the arterial layers causing an irregular expansion of the vessel in a longitudinal fashion, whereas fusiform aneurysms incorporated the entire vessel circumferentially. ${ }^{2,4}$ In the anterior circulation (AC), nonsaccular aneurysms were included if located at the MCA, A1, anterior communicating artery, and distal anterior cerebral artery segments (at or beyond the A2 segment). We aimed to focus on AC aneurysms located distal to the circle of Willis because the indication for treatment with FD is still debated and is considered off-label. In fact, the efficacy of flow diverters in the ICA segment has already been reported, ${ }^{5}$ and the US Food and Drug Administration approved their use for unruptured saccular wide-neck or fusiform aneurysms in the ICA from the petrous segment to the terminus (https://www.accessdata.fda.gov/cdrh_ docs/pdf17/P170024A.pdf). Accordingly, aneurysms arising from the petro-/cavernous and supraclinoid portions of the ICA (including the posterior communicating, anterior choroidal, and ophthalmic segments) were not included in this review.

Among the posterior circulation (PC), nonsaccular aneurysms were located at the vertebral, basilar, P1-P2, PICA, and AICA/ superior cerebellar artery segments. Series reporting giant dolichoectatic aneurysms involving the entire vertebrobasilar artery (uniform dilation involving the entire vertebrobasilar system) were not included. Reasons behind the exclusion of these lesions are the following: 1) The natural history and treatment-related outcomes have been reported to be poor, and 2) indications for treatment still remain debatable. ${ }^{6}$

Other exclusion criteria were the following: 1) case reports, 2) review articles, 3) studies published in languages other than English, 4) in vitro studies and animal studies, and 5) series reporting saccular aneurysms. In cases of overlapping patient populations, we selected series with the largest number of subjects or with the most detailed data. The analysis was conducted by 2 independent readers. Articles were screened in their entirety to determine eligibility for inclusion. In addition, a third author solved potential discrepancies.

\section{Data Collection}

We extracted the following: 1) rate of aneurysm occlusion, 2) rate of complications, and 3) clinical outcomes.
Adequate aneurysm occlusion (complete/near-complete occlusion) was defined on the basis of the O'Kelly-Marotta grades $\mathrm{C}-\mathrm{D},{ }^{7}$ the Raymond-Roy scale (class I-II), ${ }^{8}$ or when the terms "complete occlusion" or "neck remnant" were used in the study. Treatment-related complications were classified as following: 1) periprocedural (within 30 days after treatment) and delayed events (after 30 days); 2) transient complications (asymptomatic events or complete neurologic recovery) and permanent events (symptomatic complications with permanent deficits); and 3) hemorrhagic and ischemic complications. Aneurysms were classified as small and large lesions $(<10$ and $\geq 10 \mathrm{~mm}$, respectively). Arteries covered by the stents were evaluated and classified as the following: 1) normal diameter, 2) arterial narrowing, and 3) arterial occlusion. Good outcome was defined as a modified Rankin Scale score of $0-2$ or in the absence of adverse events.

\section{Outcomes Analysis}

The primary objectives of this meta-analysis study were to describe treatment-related complications (the safety of the treatment), the technical success rate, and occlusion during follow-up (efficacy of the treatment) after FD for nonsaccular aneurysms. The influence of aneurysm size, patient age, and treatment characteristics on the analyzed outcomes was also studied. This objective was achieved by performing a preplanned subgroups analysis as well as univariate and multivariate analyses on the available individual patient data. Individual patient data were extracted from each series (tables or on-line tables) when reported by the authors.

\section{Quality Scoring}

The Newcastle-Ottawa Scale 9 was used to evaluate the quality of the included studies (details in On-line Table 3). Two authors independently performed the quality assessment, while a third author solved potential discrepancies.

\section{Statistical Analysis}

Meta-Analysis. Given the interstudy differences (patient population, aneurysm characteristics, and type of device used), random effects meta-analysis was adopted to report the studied outcomes because this model incorporates heterogeneity among studies. From each cohort, the cumulative prevalence and 95\% confidence interval were calculated for each outcome. Heterogeneity was studied and was assessed by the Higgins index $\left(\mathrm{I}^{2}\right)$; subsequently, the DerSimonian and Laird random effects model was applied. The graphic representation was mostly performed by forest plot. In addition, we used subgroup analysis to estimate heterogeneity (aneurysm size, patient age, number of flow diverters, additional coils). To evaluate the risk of bias, we used a funnel plot followed by the Egger linear regression test. To verify the consistency of the meta-analysis outcome, we assessed the influence of each individual study by a sensitivity analysis ("leave-oneout" approach). Differences between subgroups of analyses were considered significant at $P<.05$. Meta-analysis was performed with ProMeta-2 (Internovi, Cesena, Italy) and OpenMeta [Analyst] (http://www.cebm.brown.edu/openmeta/).

Univariate and Multivariate Analysis. From the individual patient data, we extracted the following dependent variables: aneurysm occlusion (adequate-versus-incomplete occlusion) and treatment- 


\begin{tabular}{|c|c|c|c|}
\hline Variables & $\begin{array}{c}\text { Results of Systematic } \\
\text { Review and Meta-Analysis }\end{array}$ & $\begin{array}{l}\text { No. of } \\
\text { Articles }\end{array}$ & $\begin{array}{c}\text { Statistic } \\
(95 \% \mathrm{CI})\left(\mathrm{I}^{2}\right)\end{array}$ \\
\hline \multicolumn{4}{|l|}{ Angiographic outcomes } \\
\hline Rate of successful stent deployment & $178 / 181=96 \%$ & 11 & $(93-98)\left(1^{2}=0 \%\right)$ \\
\hline Long-term aneurysm adequate occlusion rate & $137 / 168=85.3 \%$ & 12 & $(78.2-92.4)\left(1^{2}=42.3 \%\right)$ \\
\hline Long-term aneurysm complete occlusion rate & $128 / 168=78.8 \%$ & 12 & $(72.8-84.8)\left(1^{2}=0 \%\right)$ \\
\hline Long-term adequate occlusion rate (fusiform aneurysms) & $116 / 146=83 \%$ & 11 & $(74-92)\left(1^{2}=48 \%\right)$ \\
\hline Long-term adequate occlusion rate (dissecting aneurysms) & $33 / 36=89 \%$ & 4 & $(80-98)\left(1^{2}=0 \%\right)$ \\
\hline Long-term occlusion rate among anterior circulation & $51 / 61=87.5 \%$ & 6 & $(79-95)\left(1^{2}=0 \%\right)$ \\
\hline Long-term occlusion rate among posterior circulation & $86 / 107=83 \%$ & 6 & $(71-95)\left(1^{2}=60 \%\right)$ \\
\hline Long-term adequate occlusion rate (PED) & $118 / 149=82 \%$ & 8 & $(75-90)\left(1^{2}=25 \%\right)$ \\
\hline Long-term adequate occlusion rate (other devices) & $21 / 23=90 \%$ & 3 & $(81-98)\left(1^{2}=0 \%\right)$ \\
\hline \multicolumn{4}{|l|}{ Treatment-related complications and clinical outcomes } \\
\hline Overall treatment-related complications & $41 / 213=17.4 \%$ & 16 & $(12.5-22.4)\left(I^{2}=0 \%\right)$ \\
\hline Transient complications & $21 / 213=9 \%$ & 15 & $(5.6-13)\left(1^{2}=0 \%\right)$ \\
\hline Permanent complications & $20 / 213=8 \%$ & 15 & $(5-12)\left(1^{2}=0 \%\right)$ \\
\hline Ischemic complications & $37 / 213=15 \%$ & 15 & $(10-20)\left(1^{2}=0 \%\right)$ \\
\hline Hemorrhagic complications & $4 / 213=3 \%$ & 15 & $(1.2-6)\left(1^{2}=0 \%\right)$ \\
\hline Treatment-related complications (fusiform aneurysms) & $35 / 162=17 \%$ & 11 & $(10-25)\left(I^{2}=24 \%\right)$ \\
\hline Treatment-related complications (dissecting aneurysms) & $11 / 51=19 \%$ & 4 & $(10-31)\left(1^{2}=0 \%\right)$ \\
\hline Treatment-related complications among anterior circulation & $13 / 81=14 \%$ & 8 & $(7-22)\left(I^{2}=0 \%\right)$ \\
\hline Treatment-related complications among posterior circulation & $28 / 132=20 \%$ & 8 & $(3-13)\left(1^{2}=0 \%\right)$ \\
\hline Treatment-related complications (PED) & $19 / 110=15 \%$ & 9 & $(9-21)\left(1^{2}=0 \%\right)$ \\
\hline Treatment-related complications (other devices) & $3 / 23=12 \%$ & 3 & $(6-24)\left(1^{2}=0 \%\right)$ \\
\hline Periprocedural/early complications (within 30 days) & $10 / 213=2.5 \%$ & 15 & $(1-4)\left(I^{2}=0 \%\right)$ \\
\hline Delayed complications (after 30 days) & $31 / 213=12 \%$ & 15 & $(7-17)\left(1^{2}=35 \%\right)$ \\
\hline Premature discontinuation of AT and related ischemic events & $5 / 93=5 \%$ & 8 & $(2-9)\left(1^{2}=0 \%\right)$ \\
\hline Treatment-related mortality & $1 / 213=2 \%$ & 15 & $(0.2-3.5)\left(1^{2}=0 \%\right)$ \\
\hline Overall rate of good neurologic outcome & $154 / 187=87 \%$ & 10 & $(79-95)\left(1^{2}=60 \%\right)$ \\
\hline Occlusion of covered branches & $5 / 72=7 \%$ & 10 & $(2-13)\left(1^{2}=0 \%\right)$ \\
\hline Symptoms related to occlusion or impaired flow of covered branches & $3 / 72=3 \%$ & 10 & $(0.5-9)\left(1^{2}=0 \%\right)$ \\
\hline
\end{tabular}

Note:-AT indicates antiplatelet therapy.

related complications (complications versus no complications). Individual patient data were selected from patients with nonsaccular aneurysms. The $\chi^{2}$ test was used to evaluate qualitative factors associated with occlusion and complications (aneurysm location and size, type of stent, patient age, type of aneurysm). The independent variables significantly associated $(P \leq .1$ in the univariate analysis) with aneurysm complete occlusion or complications were analyzed together in a binary logistic regression (multivariate analysis) to assess the independent contribution of each factor. The results of the regression model were calculated by the Wald test and expressed using $P$ values and the related odds ratios. All statistical analyses were performed with SPSS, Version 24 (IBM, Armonk, New York).

\section{RESULTS}

\section{Literature Review}

Studies included in our meta-analysis are summarized in On-line Table 2. The search flow diagram is shown in On-line Fig 1.

A total of 15 studies and 213 unruptured nonsaccular intracranial aneurysms treated with FD were included. We extracted $81 \mathrm{AC}$ and $132 \mathrm{PC}$ nonsaccular aneurysms treated with FD techniques.

\section{Quality of Studies}

Overall, 14 studies were retrospective series, ${ }^{4,10-22}$ whereas 1 study was a prospective multicenter trial. ${ }^{23}$ On the basis of the Newcastle-Ottawa Quality Assessment Scale, 10 studies $^{4,10,12-17,21,23}$ were rated as "high-quality" (On-line Table 3).

\section{Patient Population and Aneurysm Characteristics}

The mean age of patients was 52.5 years (range, $18-82$ years), and the proportion of male patients was $42 \%$ (95\% CI, 35\%-49\%) (On-line Table 4). The mean aneurysm size was $11 \mathrm{~mm}$ (median, $10 \mathrm{~mm}$; range, 5-22 mm). The proportion of fusiform and dissecting aneurysms was 76\% (162/213; 95\% CI, 69\%-81\%) and $24 \%$ (51/213; 95\% CI, 18\%-30\%), respectively. Aneurysms of the AC and PC were $38 \%(81 / 213 ; 95 \%$ CI, 31\%-44\%) and 62\% (132/ 213; 95\% CI, 55\%-68\%), respectively. Most aneurysms were located at the vertebrobasilar (97/213 $=45.5 \%$; $95 \%$ CI, $38 \%-$ $52 \%)$ and MCA segments $(69 / 213=32.5 \%$; 95\% CI, 26\%-38\%). The most common device was the Pipeline Embolization Device (PED; Covidien, Irvine, California) $(185 / 213=87 \%$; $95 \% \mathrm{CI}$, $81 \%-90 \%)$.

The mean radiologic (DSA) follow-up was 13 months (range, 4-24 months; median, 12 months; interquartile range [IQR], 712 months), and the mean clinical follow-up was 14 months (range, 6-28 months; median, 12 months; IQR, 8-15 months).

\section{Angiographic Outcomes}

The technical success rate was $96 \%$ (178/181; 95\% CI, 93\%-98\%; $\mathrm{I}^{2}=0 \%$ ) (Table 1). The rates of long-term adequate and complete occlusion were $85.3 \%$ (137/168; 95\% CI, 78.2\%-92.4\%; $\mathrm{I}^{2}=$ $42.3 \%$ ) and $78.8 \%$ (128/168; 95\% CI, $72.8 \%-84.8 \%$; $\left.\mathrm{I}^{2}=0 \%\right)$. Meta-regression showed a nonsignificant variation of the effect size $(P=.71)$ during the analyzed period, and the funnel plot (Egger linear regression test) reasonably excluded publication bias $(P=.52)$. The sensitivity analysis showed that no individual 


\begin{tabular}{|c|c|c|c|c|c|}
\hline & \multirow[b]{2}{*}{ Univariate, $P$ Value } & \multirow[b]{2}{*}{ Univariate, OR } & \multicolumn{3}{|c|}{ Multivariate } \\
\hline & & & Odds Ratio & $95 \% \mathrm{Cl}$ & $P$ Value \\
\hline \multicolumn{6}{|l|}{ Independent variables for occlusion } \\
\hline Type of FD (PED vs other) & 0.22 & 1.2 & & & \\
\hline Patient age (younger than 60 vs older than $60 \mathrm{yr}$ ) & 0.21 & 2.6 & & & \\
\hline Aneurysm size (large vs small) ${ }^{\mathrm{a}}$ & 0.13 & 1.7 & 1.5 & $0.2-6.4$ & .81 \\
\hline Type of aneurysm (dissecting vs fusiform) & 0.06 & 2.5 & 1.7 & $0.4-2.4$ & .35 \\
\hline Aneurysm location (AC vs PC) & 0.11 & 3.1 & 0.5 & $0.2-0.7$ & .38 \\
\hline \multicolumn{6}{|l|}{ Independent variables for complications } \\
\hline Type of FD (PED vs other) & 0.94 & 1.1 & & & \\
\hline Patient age (younger than 60 vs older than $60 \mathrm{yr}$ ) & 0.46 & 1.5 & & & \\
\hline Aneurysm size (large vs small) ${ }^{\mathrm{a}}$ & 0.03 & 4.5 & 6.6 & $1.3-15$ & .02 \\
\hline Type of aneurysm (fusiform vs dissecting) & 0.27 & 0.8 & & & \\
\hline Aneurysm location (AC vs PC) & 0.04 & 0.7 & 0.3 & $0.6-1.8$ & .09 \\
\hline
\end{tabular}

Note:-OR indicates odds ratio.

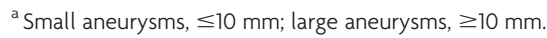

study significantly influenced the combined aneurysm occlusion rate (On-line Fig 2).

The long-term adequate occlusion rate (O'Kelly-Marotta CD) among fusiform lesions was 83\% (116/146; 95\% CI, 74\%-92\%; $\left.\mathrm{I}^{2}=48 \%\right)$, whereas among dissecting aneurysms, it was $89 \%(33 /$ 36; 95\% CI, 80\%-98\%; $\left.\mathrm{I}^{2}=0 \%\right)(P=.31)$. Complete/near-complete occlusion among the AC and PC was $87.5 \%(51 / 61 ; 95 \% \mathrm{CI}$, 79\%-95\%; $\left.\mathrm{I}^{2}=0 \%\right)$ and 83\% (86/107; 95\% CI, 71\%-95\%; $\mathrm{I}^{2}=$ 60\%) $(P=.45)$, respectively. Long-term adequate occlusion was $82 \%\left(118 / 149 ; 95 \% \mathrm{CI}, 75 \%-90 \% ; \mathrm{I}^{2}=25 \%\right)$ and $90 \%(21 / 23$; 95\% CI, 81\%-98\%; $\left.\mathrm{I}^{2}=0 \%\right)(P=.31)$ after treatment with the $\mathrm{PED}$ and other stents, respectively.

\section{Treatment-Related Complications}

The overall complication rate was $17.4 \%$ (41/213; 95\% CI, $12.45 \%-22.4 \%$; $\mathrm{I}^{2}=0 \%$ ) (Table 1). Meta-regression showed a nonsignificant variation of the effect size $(P=.62)$ over the analyzed period, and the funnel plot (the Egger linear regression test) reasonably excludes publication bias $(P=.24)$. In addition, no individual study significantly influenced the treatment-related complication rate (On-line Fig 3).

Periprocedural/early complications were $2.5 \%$ (10/213; $95 \%$ CI, $1 \%-4 \%$; $\left.\mathrm{I}^{2}=0 \%\right)$. Delayed complications were $12 \%(31 / 213$; 95\% CI, 7\%-17\%; $\mathrm{I}^{2}=35 \%$ ). Transient and permanent complications were $9 \%\left(21 / 213 ; 95 \%\right.$ CI, $5.6 \%-13 \%$; $\left.\mathrm{I}^{2}=0 \%\right)$ and $8 \%$ (20/213; 95\% CI, 5\%-12\%; $\mathrm{I}^{2}=0 \%$ ), respectively (description of the adverse events is reported in On-line Table 2).

Overall, ischemic/thromboembolic and hemorrhagic events were $15 \%\left(37 / 213 ; 95 \% \mathrm{CI}, 10 \%-20 \%\right.$; $\left.\mathrm{I}^{2}=0 \%\right)$ and $3 \%(4 / 213$; $95 \%$ CI, $\left.1.2 \%-6 \% ; I^{2}=0 \%\right)$, respectively. Treatment-related complications among fusiform and dissecting aneurysms were $17 \%$ (35/162; 95\% CI, 10\%-25\%; $\left.\mathrm{I}^{2}=24 \%\right)$ and 19\% (11/51; 95\% CI, $\left.10 \%-31 \% ; \mathrm{I}^{2}=0 \%\right)(P=.71)$, respectively. PC lesions were associated with slightly higher rates of complications compared with AC lesions $\left(28 / 132=20 \%\right.$; $95 \%$ CI, $3 \%-13 \%$; $\mathrm{I}^{2}=0 \%$ versus 13 / $81=14 \%$; 95\% CI, 7\%-22\%; $\left.\mathrm{I}^{2}=0 \%\right)(P=.22)$. Treatment with the PED and other stents was associated with 15\% (19/110; 95\% CI, 9\%-21\%; $\left.\mathrm{I}^{2}=0 \%\right)$ and $12 \%\left(3 / 23\right.$; 95\% CI, 6\%-24\%; $\mathrm{I}^{2}=$ $0 \%)$ rates of complications $(P=.76)$, respectively.

The rate of ischemic events after discontinuation of the antiplatelet therapy was $5 \%\left(5 / 93 ; 95 \% \mathrm{CI}, 2 \%-9 \% ; \mathrm{I}^{2}=0 \%\right)$. There were no cases of early or delayed rupture after treatment among the analyzed series.

Treatment-related mortality was $2 \%(1 / 213 ; 95 \%$ CI, $0.2 \%-3.5 \%$; $\left.\mathrm{I}^{2}=0 \%\right)$, and the rate of good neurologic outcome was $87 \%$ (154/ $187 ; 95 \%$ CI, 79\%-95\%; $\mathrm{I}^{2}=60 \%$ ). Finally, the rate of occlusion of branches covered by flow diverters was $7 \%$ (5/72; $95 \%$ CI, $2 \%-13 \%$; $\left.I^{2}=0 \%\right)$, with $3 \%\left(3 / 72 ; 95 \%\right.$ CI, $\left.0.5 \%-9 \% ; I^{2}=0 \%\right)$ of symptoms related to the impaired flow on the covered vessel.

\section{Subgroup Analysis: Factors Related to Aneurysm Occlusion and Complications}

Occlusion and complication rates were compared between the following preplanned subgroups: FD alone versus FD + coils, single flow diverter versus multiple flow diverters, mean patient age, and small-versus-large aneurysms. The occlusion rate was comparable among all the studied subgroups. The complication rate was higher among large aneurysms $(\geq 10 \mathrm{~mm})$ compared with small $(<10 \mathrm{~mm})$ lesions $(P=.04)$ (On-line Table 5).

Overall, individual patient data were available for $80 \%$ of patients (Table 2). The following factors were tested in the univariate and multivariate analyses: type of FD (PED versus other), patient age (younger than 60 versus older than 60 years), aneurysm size ( $>10$ versus $<10 \mathrm{~mm}$ ), fusiform versus dissecting, and aneurysm location (AC versus $\mathrm{PC}$ ). In the multivariate analysis, none of the above-reported factors were independently associated with the occlusion rate, whereas the aneurysm size $(>10$ versus $<10 \mathrm{~mm}$ ) was independently associated with the complication rate $(\mathrm{OR}=6.6$; $95 \% \mathrm{CI}, 1.3 \%-15 \% ; P=.02)$.

\section{Study Heterogeneity}

Heterogeneity was low $(<50 \%)$ for all the reported outcomes except for the following: the overall rate of good neurologic outcome and the mean difference of age among completely and incompletely occluded aneurysms.

\section{DISCUSSION}

After we pooled data from 15 studies and 213 aneurysms, our meta-analysis is the largest study investigating outcomes after FD for unruptured nonsaccular lesions. Particularly, this study aimed to improve the knowledge of angiographic and clinical outcomes 
after FD for fusiform/dissecting lesions located both in the PC and in distal segments of the AC.

\section{Angiographic Outcome}

A very recent meta-analysis of 500 distal unruptured AC aneurysms demonstrated the efficacy of $\mathrm{FD}$, reporting a rate of adequate occlusion close to $83 \%{ }^{24}$ However, saccular and nonsaccular aneurysms were pooled together, and fusiform/dissecting lesions were underrepresented in this review. ${ }^{24}$ Kiyofuji et $\mathrm{al}^{25}$ performed a meta-analysis of 131 nonsaccular PC aneurysms, reporting a 50\% rate of complete/near-complete occlusion. This rate appears quite low compared with the general occlusion rate of $80 \%$ reported in others series and a meta-analysis of FD. ${ }^{26}$ The lower occlusion rate in the review of Kiyofuji et al may reflect the inclusion of giant dolichoectatic aneurysms (involving all the vertebrobasilar system). These aneurysms remain one of the most formidable lesions to treat: Natural history is reported to be poor (mortality rates at 5 years are close to $30 \%$ ), complication rates are quite high, and the indication for treatment is still debatable. ${ }^{6}$

Our meta-analysis, excluding dolichoectatic holobasilar lesions and aneurysms arising from the ICA segment, showed $85 \%$ of complete/near-complete occlusion (O'Kelly-Marotta C-D), with comparable rates in the anterior and posterior circulations. Although most of the included series classified nonsaccular aneurysms into fusiform and dissecting lesions, the diagnosis may not be correct in all cases because fusiform shape may represent a variety of different histopathologic pictures. Mizutani et $\mathrm{al}^{2}$ classified 85 aneurysms unrelated to the branching zones into 4 types: Type 1 aneurysms were defined as "classic dissecting" lesions; type 2 indicated a fusiform segmental ectasia; and types 3 and 4 represented dolichoectatic and "blisterlike" aneurysms. In our review, unruptured dissecting aneurysms presented a slightly higher (89\%) rate of occlusion compared with fusiform lesions (83\%), though the meta-analysis was likely underpowered to highlight a statically significant difference. Griessenauer et $\mathrm{al}^{4}{ }^{4}$ in a series of 131 PC aneurysms, reported $83 \%$ and $64 \%$ complete occlusion after treatment with the PED of 29 dissecting and 53 fusiform lesions, respectively. Similarly, Lin et $\mathrm{al}^{10}$ described a series of 15 fusiform and 5 dissecting aneurysms of the MCA and anterior cerebral artery segments, reporting $73 \%$ and $100 \%$ complete occlusion after treatment with the $\mathrm{PED}$, respectively.

In the univariate analysis, there was a trend toward higher occlusion rates in favor of dissecting aneurysms, though the multivariate logistic regression did not show any significant association among the occlusion rate and the analyzed factors.

\section{Treatment-Related Complications}

The overall rate of complications of $17 \%$ found in our meta-analysis appears quite high compared with series of flow diversion for saccular aneurysms. Brinjikji et $\mathrm{al}^{16}{ }^{16}$ in a post hoc analysis of the International Retrospective Study of the Pipeline Embolization Device (IntrePED), reported fusiform aneurysm configuration as the only variable independently associated with stroke $(\mathrm{OR}=2.7, P=.03)$. In our study, complications were similar among fusiform and dissecting types and were mostly related to ischemic events (15\%).
The anterior circulation was associated with an approximately $14 \%$ rate of adverse events. A recent meta-analysis and series of unruptured saccular anterior communicating artery and pericallosal aneurysms treated with flow diverters reported approximately $8 \%$ treatment-related complications. ${ }^{24,27,28}$ However, in our review, $90 \%$ of the nonsaccular AC aneurysms were located at the MCA. It has been reported that MCA location is associated with an approximately $18 \%$ rate of complications after FD. ${ }^{24,29}$ Accordingly, the relatively high rate of adverse events among AC fusiform/dissecting lesions found in our study can be partially influenced by the predominance of the MCA location.

Focusing on the PC, we report a $20 \%$ rate of complications after FD of nonsaccular aneurysms. This is in line with descriptions in the literature. Griessenauer et $\mathrm{al}^{4}$ reported roughly $25 \%$ and $23 \%$ adverse events among saccular and nonsaccular PC aneurysms treated with FD. In the IntrePED study, Kallmes et $\mathrm{al}^{30}$ found higher rates of morbidity and mortality after FD in PC (16.5\%) compared with AC lesions (5\%-9\%). In addition, Lopes et $\mathrm{al}^{31}{ }^{31}$ evaluating the morbidity among the subgroup of PC lesions of the IntrePED registry, showed a 19\% neurologic morbidity among the fusiform group. In our study, the univariate analysis underlined PC and large aneurysms as factors associated with higher complications, though the size was the only variable independently associated with adverse events at the binary logistic regression $(\mathrm{OR}=6.6, P=.02)$. Our meta-analysis is the first focusing on the factors associated with complications among a selected population of nonsaccular aneurysms. In the series of Griessenauer et al, ${ }^{4}$ small PC nonfusiform aneurysms presented with $17 \%$ complications, whereas large/giant lesions were associated with approximately $25 \%$ adverse events.

Finally, the 5\% rate of ischemic complications after discontinuation of the antiplatelet therapy ( 1 in-stent occlusion, 2 cases of basilar perforators infarcts, and 2 thromboembolic events) indicates the importance of the antiplatelet regimen among nonsaccular lesions treated by flow diversion.

\section{Limitations}

Our study has limitations. Most of the series are small, retrospective studies. The included series classified aneurysms into fusiform and dissecting types; however, few studies reported a clear angiographic definition of fusiform and dissecting lesions. The antiplatelet regimen was quite comparable among the studies (On-line Table 2), but the influence of platelet inhibition was not evaluated. However, this review is the largest meta-analysis focusing on FD for nonsaccular aneurysms, providing updated data for the treatment management of these lesions.

\section{CONCLUSIONS}

Unruptured nonsaccular aneurysms located in the posterior and distal anterior circulations can be effectively treated with a flowdiversion strategy. Nevertheless, treatment-related complications are not negligible, with about $15 \%$ ischemic events and $8 \%$ morbidity. Larger size $(>10 \mathrm{~mm})$ significantly increases the risk of procedure-related adverse events among nonsaccular lesions.

Disclosures: Paolo Perrini-UNRELATED: Employment: Azienda Ospedaliero Universitaria Pisana. Alain Bonafe-UNRELATED: Consultancy: Stryker, Medtronic, 
MicroVention. Vincent Costalat-UNRELATED: Consultancy: Medtronic, Cerenovus, MicroVention; Grants/Grants Pending: Medtronic, MicroVention, Stryker; Payment for Lectures Including Service on Speakers Bureaus: Stryker, MicroVention, Medtronic; Payment for Development of Educational Presentations: Medtronic, Stryker.* Pierre-Henri Lefevre-UNRELATED: Payment for development of educational presentations: Medtronic. *Money paid to the institution.

\section{REFERENCES}

1. Awad AJ, Mascitelli JR, Haroun RR, et al. Endovascular management of fusiform aneurysms in the posterior circulation: the era of flow diversion. Neurosurg Focus 2017;42:E14 CrossRef Medline

2. Mizutani T, Miki Y, Kojima H, et al. Proposed classification of nonatherosclerotic cerebral fusiform and dissecting aneurysms. Neurosurgery 1999;45:253-59; discussion 259-60 CrossRef Medline

3. Moher D, Liberati A, Tetzlaff J, et al. Preferred reporting items for systematic reviews and meta-analyses: the PRISMA statement. Int J Surg 2010;8:336-41 CrossRef Medline

4. Griessenauer CJ, Ogilvy CS, Adeeb N, et al. Pipeline embolization of posterior circulation aneurysms: a multicenter study of 131 aneurysms. J Neurosurg 2018;130:923-35 CrossRef Medline

5. Becske T, Kallmes DF, Saatci I, et al. Pipeline for uncoilable or failed aneurysms: results from a multicenter clinical trial. Radiology 2013; 267:858-68 CrossRef Medline

6. Siddiqui AH, Abla AA, Kan P, et al. Panacea or problem: flow diverters in the treatment of symptomatic large or giant fusiform vertebrobasilar aneurysms. J Neurosurg 2012;116:1258-66 CrossRef Medline

7. O'Kelly CJ, Krings T, Fiorella D, et al. A novel grading scale for the angiographic assessment of intracranial aneurysms treated using flow diverting stents. Interv Neuroradiol 2010;16:133-37 CrossRef Medline

8. Roy D, Milot G, Raymond J. Endovascular treatment of unruptured aneurysms. Stroke 2001;32:1998-2004 CrossRef Medline

9. Wells GS, O'Connell D. The Newcastle-Ottawa Scale (NOS) for Assessing the Quality of Nonradomized Studies in Meta-Analyses. Ottawa: Ottawa Hospital Research Institute; 2011

10. Lin N, Lanzino G, Lopes DK, et al. Treatment of distal anterior circulation aneurysms with the Pipeline Embolization Device: a US multicenter experience. Neurosurgery 2016;79:14-22 CrossRef Medline

11. Lubicz B, Collignon L, Raphaeli G, et al. Pipeline flow-diverter stent for endovascular treatment of intracranial aneurysms: preliminary experience in 20 patients with 27 aneurysms. World Neurosurg 2011;76:114-19 CrossRef Medline

12. Pistocchi S, Blanc R, Bartolini B, et al. Flow diverters at and beyond the level of the circle of Willis for the treatment of intracranial aneurysms. Stroke 2012;43:1032-38 CrossRef Medline

13. Topcuoglu OM, Akgul E, Daglioglu E, et al. Flow diversion in middle cerebral artery aneurysms: is it really an all-purpose treatment? World Neurosurg 2016;87:317-27 CrossRef Medline

14. Zanaty M, Chalouhi N, Tjoumakaris SI, et al. Flow diversion for complex middle cerebral artery aneurysms. Neuroradiology 2014; 56:381-87 CrossRef Medline

15. Bhogal P, Chudyk J, Bleise C, et al. The use of flow diversion in vessels $\leq \mathbf{2 . 5} \mathbf{m m}$ in diameter: a single-center experience. World Neurosurg 2018;118:e575-83 CrossRef Medline

16. Brinjikji W, Lanzino G, Cloft HJ, et al. Risk factors for ischemic complications following Pipeline Embolization Device treatment of intracranial aneurysms: results from the IntrePED study. AJNR Am J Neuroradiol 2016;37:1673-78 CrossRef Medline

17. Bender MT, Colby GP, Jiang B, et al. Flow diversion of posterior circulation cerebral aneurysms: a single-institution series of 59 cases. Neurosurgery 2019;84:206-16 CrossRef Medline

18. Bhogal P, Perez MA, Ganslandt O, et al. Treatment of posterior circulation non-saccular aneurysms with flow diverters: a single-center experience and review of 56 patients. J Neurointerv Surg 2017; 9:471-81 CrossRef Medline

19. Munich SA, Tan LA, Keigher KM, et al. The Pipeline Embolization Device for the treatment of posterior circulation fusiform aneurysms: lessons learned at a single institution. J Neurosurg 2014; 121:1077-84 CrossRef Medline

20. Natarajan SK, Lin N, Sonig A, et al. The safety of Pipeline flow diversion in fusiform vertebrobasilar aneurysms: a consecutive case series with longer-term follow-up from a single US center. $J$ Neurosurg 2016;125:111-19 CrossRef Medline

21. Wallace AN, Grossberg JA, Almandoz JED, et al. Endovascular treatment of posterior cerebral artery aneurysms with flow diversion: case series and systematic review. Neurosurgery 2018;83:79099 CrossRef Medline

22. Wallace AN, Kamran M, Madaelil TP, et al. Endovascular treatment of posterior inferior cerebellar artery aneurysms with flow diversion. World Neurosurg 2018;114:e581-87 CrossRef Medline

23. Mohlenbruch MA, Kizilkilic O, Killer-Oberpfalzer M, et al. Multicenter experience with FRED Jr Flow Re-Direction Endoluminal Device for intracranial aneurysms in small arteries. AJNR Am J Neuroradiol 2017;38:1959-65 CrossRef Medline

24. Cagnazzo F, Perrini P, Dargazanli C, et al. Treatment of unruptured distal anterior circulation aneurysms with flow-diverter stents: a meta-analysis. AJNR Am J Neuroradiol 2019;40:687-93 CrossRef Medline

25. Kiyofuji S, Graffeo CS, Perry A, et al. Meta-analysis of treatment outcomes of posterior circulation non-saccular aneurysms by flow diverters. J Neurointerv Surg 2018;10:493-49 CrossRef Medline

26. Brinjikji W, Murad MH, Lanzino G, et al. Endovascular treatment of intracranial aneurysms with flow diverters: a meta-analysis. Stroke 2013;44:442-47 CrossRef Medline

27. Cagnazzo F, Limbucci N, Nappini S, et al. Flow-diversion treatment of unruptured saccular anterior communicating artery aneurysms: a systematic review and meta-analysis. AJNR Am J Neuroradiol 2019;40:497-502 CrossRef Medline

28. De Macedo Rodrigues K, Kuhn AL, Tamura T, et al. Pipeline Embolization Device for pericallosal artery aneurysms: a retrospective single center safety and efficacy study. Oper Neurosurg (Hagerstown) 2018;14:351-58 CrossRef Medline

29. Cagnazzo F, Mantilla D, Lefevre PH, et al. Treatment of middle cerebral artery aneurysms with flow-diverter stents: a systematic review and meta-analysis. AJNR Am J Neuroradiol 2017;38:228994 CrossRef Medline

30. Kallmes DF, Hanel $\mathrm{R}$, Lopes $\mathrm{D}$, et al. International retrospective study of the Pipeline Embolization Device: a multicenter aneurysm treatment study. AJNR Am J Neuroradiol 2015;36:108-15 CrossRef

31. Lopes DK, Jang DK, Cekirge S, et al. Morbidity and mortality in patients with posterior circulation aneurysms treated with the Pipeline Embolization Device: a subgroup analysis of the international retrospective study of the Pipeline Embolization Device. Neurosurgery 2018;83:488-500 CrossRef Medline 